\title{
Cross-Slot Antenna with U-Shaped Tuning Stub for Ultra-Wideband Applications
}

\author{
Dawood Seyed Javan, Mohammad Ali Salari, and Omid Hashemi Ghoochani \\ Department of Electrical Engineering, Islamic Azad University, Mashhad 16669 76113, Iran \\ Correspondence should be addressed to Dawood Seyed Javan, dawoodjavan@yahoo.com
}

Received 10 January 2008; Accepted 30 June 2008

Recommended by Karu Esselle

A novel design of an ultra-wideband (UWB) slot antenna is presented. This antenna operates as a transmitter and receiver antenna. Effects of the antenna dimensional parameters are studied through experimental and simulation results. Design procedures are developed and verified for different frequency bands. The experimental and simulation results exhibit good impedance bandwidth, radiation pattern, and relatively constant gain over the entire band of frequency. Antenna gain and directivity at boresight and in their maximum states are close to each other and indicate high radiation efficiency. To use the antenna as a linearly polarized antenna, the radiation pattern in E-plane is better than that in $\mathrm{H}$-plane.

Copyright ( $\odot 2008$ Dawood Seyed Javan et al. This is an open access article distributed under the Creative Commons Attribution License, which permits unrestricted use, distribution, and reproduction in any medium, provided the original work is properly cited.

\section{INTRODUCTION}

The Federal Communication Commission (FCC) issued a ruling for ultra-wideband (UWB) implementation in data communication [1]. A UWB technology promotes communication systems, particularly in wireless multimedia systems with high data rate. According to FCC, a UWB antenna should provide a gain and impedance bandwidth from 3.1 to 10.6 GHz. A microstrip slot antenna may be a good choice as it is low-profile, low-cost, lightweight, easy integration with monolithic microwave integrated circuits (MMICs). Feed interactions of wideband slot antennas are analyzed using finite element-optimization methods and effects of feeding mechanisms on dimensions of slots have been discussed in [2]. Several methods have been proposed to increase the bandwidth of microstrip-fed slot or cavity-backed slot antenna, such as printed radial stub [3]. A printed wideslot antenna is fed by a microstrip line with a fork-like tuning stub for bandwidth enhancement [4]. A design of a microstrip-line-fed printed wide-slot antenna had been studied in [5]. An ultra-wideband coplanar-waveguide(CPW-) fed slot antenna was excited by a $50-\Omega$ CPW with a U-shaped tuning stub [6]. Experimental investigations on a wideband slot antenna element have been proposed [7] as a building block for designing single- or multielement wideband or dual-band slot antennas. This element shows bandwidth values up to $37 \%$, if used in the wideband mode.
A circular slot antenna is fed by a circular open-ended microstrip line to provide UWB impedance bandwidth [8]. Also an ultra-wideband square-ring slot antenna (SRSA) has been proposed which is fed by a microstrip line with a $\mathrm{U}$ shaped tuning stub [9]. However, the SRSA is split inside the U-shaped feed, so it is called split square-ring slot antenna (SSRSA). A printed rectangular slot antenna with a Ushaped tuning stub is backed with reflector for improvement in the impedance bandwidth and unidirectional radiation patterns [10].

In this paper, we propose a novel structure that is driven by wide-slot antenna and merged by a cross-slot for improvement in gain and impedance bandwidth. The measurement and simulation results of the impedance bandwidth are in good agreement with each other.

\section{ANTENNA STRUCTURE}

Figure 1 shows the proposed printed slot antenna. The antenna structure is a split square-ring slot in the ground plane of dielectric substrate with a cross-slot in the center of the square ring. This structure is fed by a single microstrip line with a U-shaped tuning stub. The slot antenna is fed near an edge by a microstrip line and a fictitious short circuit that produces more resonant frequencies [7].

The SSRSA can be considered as a combination of numbers of narrow slot radiators which are connected to 


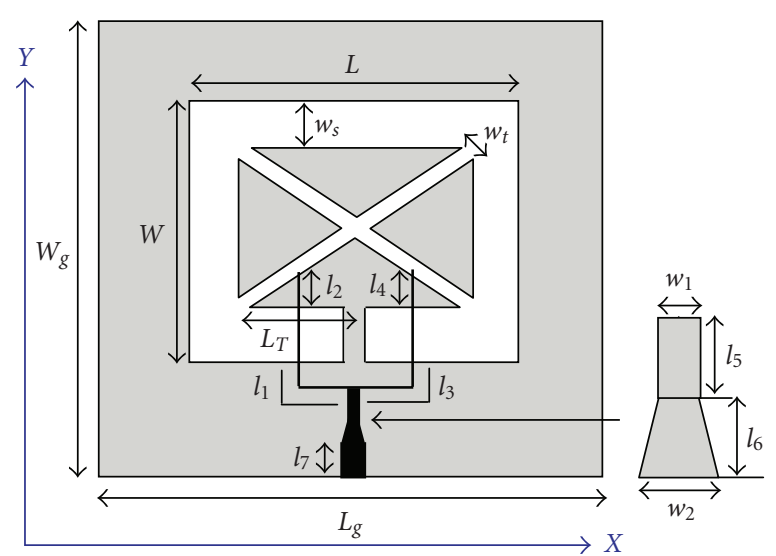

FIGURE 1: Configuration of the proposed antenna.

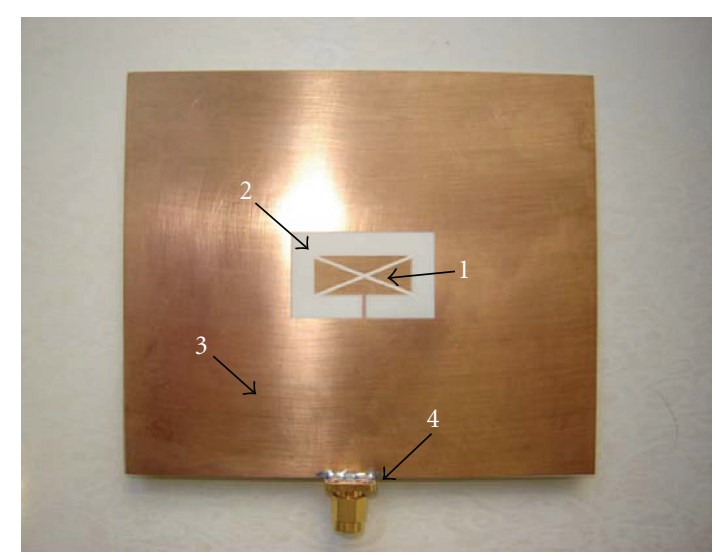

FIGURe 2: Photograph of the antenna: (1) cross-slot; (2) square slot; (3) ground plane; (4) input port is connected to microstrip line.

each other, so it can provide a couple of resonances at different frequencies. The split in one arm actually increases the number of resonances by introducing new resonant lengths. The cross-slot is located in the center of the square ring. Actually, the combination of the cross slot and square ring slot can create more resonant frequencies and this promotes the impedance matching rather than [9]. This structure is fabricated on a $0.5 \mathrm{~mm} \mathrm{RO} 4003 \mathrm{~B}$ substrate with a dielectric constant equal to 3.4. A photograph of the proposed antenna is shown in Figure 2. The antenna includes a microstrip feed line with the U-shaped tuning stub. By splitting the square-ring slot antenna (SRSA) and optimizing the feeding network, the required impedance bandwidth is achieved over the UWB frequency range (3.1 to $10.6 \mathrm{GHz}$ ). The ground plane size is $L g \times W g=100 \mathrm{~mm} \times$ $100 \mathrm{~mm}$.

\section{RESULTS AND DISCUSSIONS}

Effect of $L_{T}$ variations on the return loss of antenna, which has been evaluated by IE3D software [11], is shown in Figure 3.

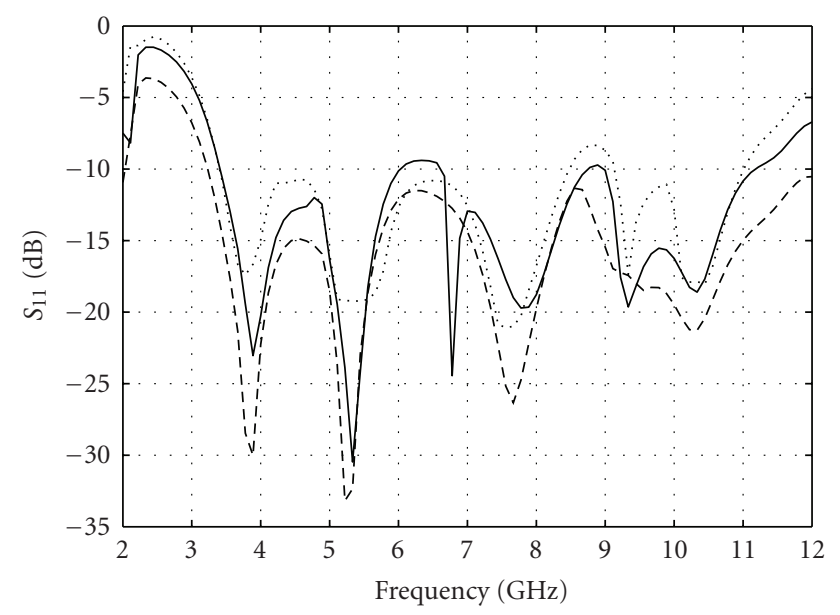

$$
\begin{aligned}
\cdots \cdots & L_{T}=3 \mathrm{~mm} \\
- & L_{T}=8 \mathrm{~mm} \\
--- & L_{T}=13 \mathrm{~mm}
\end{aligned}
$$

Figure 3: Effect of $L_{T}$ changes on return loss. $L_{T}$ is the distance between the center of the cross-slot and the square ring.

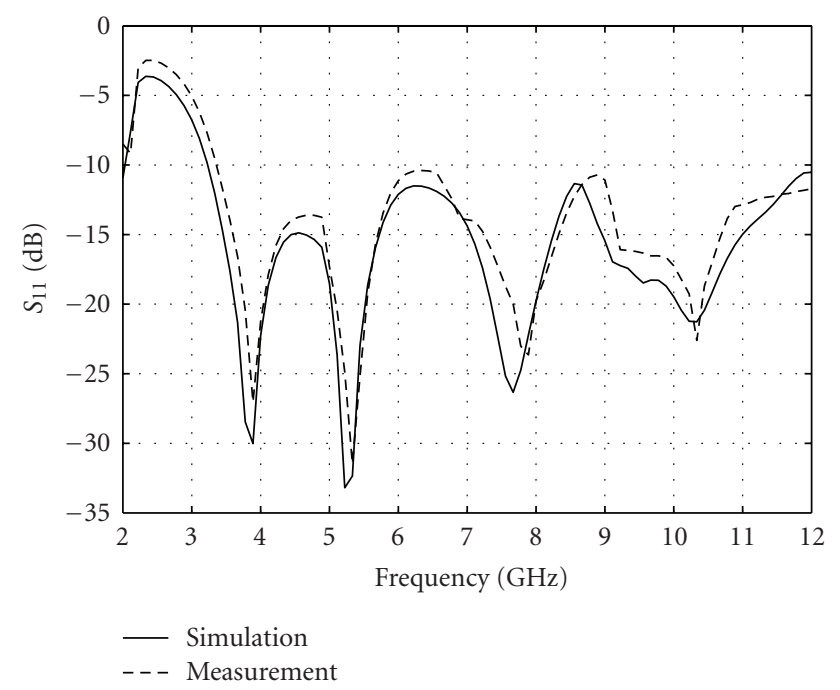

FIGURE 4: Measured and simulated return loss of proposed antenna.

The longer the $L_{T}$, the better the impedance matching, for the coupling between the square ring and the cross-slot.

It is obvious that the upper resonances are created by offcenter microstrip feed [7].

The U-shaped tuning stub is employed for wideband performance. The impedance matching of the proposed antenna is unfavorable when the $L_{T}$ is less than $13 \mathrm{~mm}$. The prototype antenna was simulated by IE3D software and fabricated with $L_{T}=13 \mathrm{~mm}$ and $W_{t}=1 \mathrm{~mm}$. The simulation and measurement results are shown in Figure 4.

The resonant frequencies of the simulation and measurement results are in good agreement within the matching frequency band $3 \mathrm{GHz}$ to $12 \mathrm{GHz}$, which corresponds to the impedance bandwidth $\left(S_{11}<-10 \mathrm{~dB}\right)$. This structure 
TABLE 1: The dimensions of proposed antenna to $\mathrm{mm}$.

\begin{tabular}{|c|c|c|c|c|c|c|c|c|c|c|c|c|c|c|}
\hline Parameter & $W$ & $W_{s}$ & $W_{1}$ & $W_{2}$ & $W_{t}$ & $L$ & $l_{1}$ & $l_{2}$ & $l_{3}$ & $l_{4}$ & $l_{5}$ & $l_{6}$ & $l_{7}$ & $L_{T}$ \\
\hline Magnitude (mm) & 21 & 6 & 0.7 & 13 & 1 & 35 & 14.3 & 3 & 14 & 4.1 & 0.6 & 1.8 & 30 & 13 \\
\hline
\end{tabular}
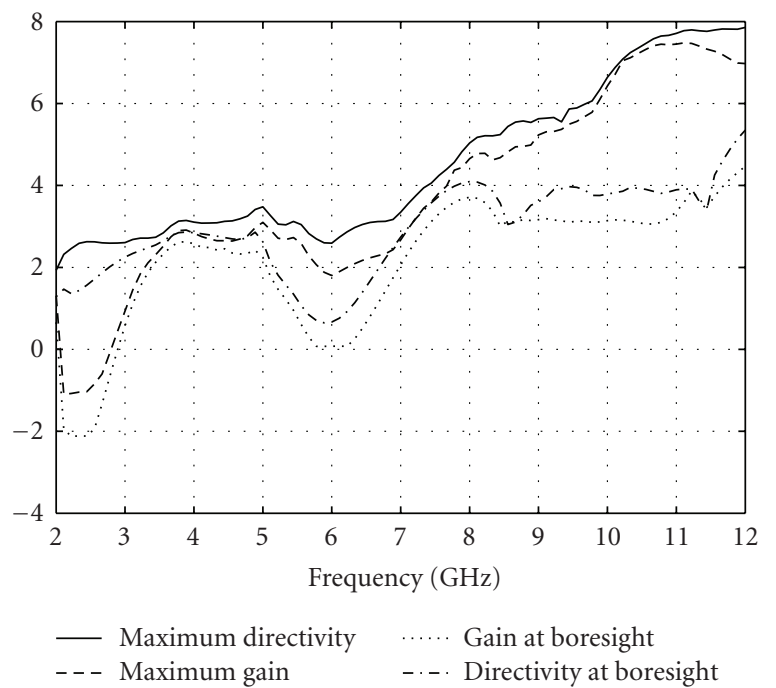

FIGURE 5: Simulated values of gain and values of directivity (dBi).

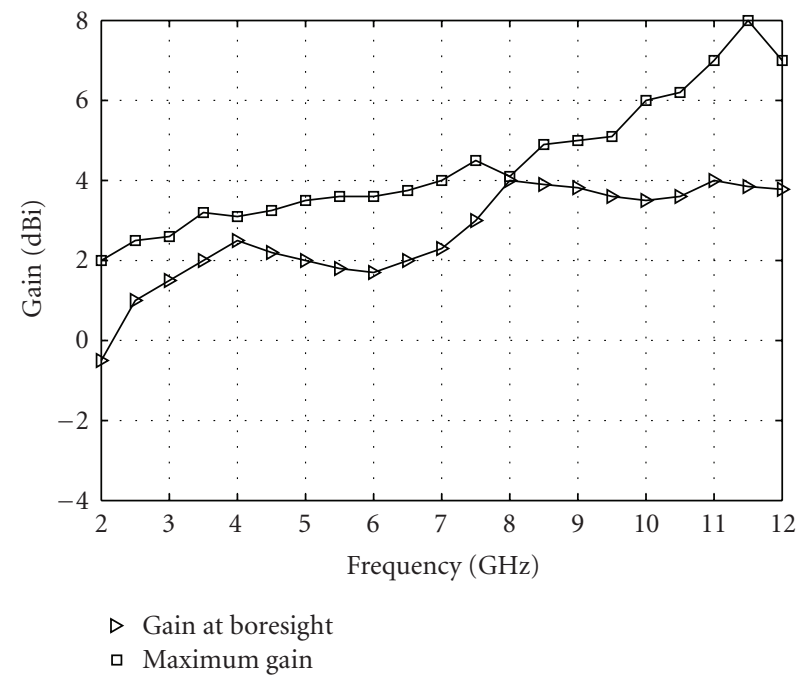

FIGURE 6: Measured values of the gain.

is more compact than that in [8]. The antenna provides a VSWR lower than $2\left(S_{11}<-10 \mathrm{~dB}\right)$ from 3 to $12 \mathrm{GHz}$.

The parameter dimensions are obtained after performing an optimization and identified in Table 1. These dimensions were obtained by performing an optimization for improving the impedance bandwidth by ADS software [12]. Figure 5 shows the gain of optimized antenna at broadside $(\varphi=$ $0, \theta=0$ ) from 2 to $12 \mathrm{GHz}$. The directivity at the direction of maximum radiation is shown in this figure. The antenna gain and directivity at boresight and in their maximum states are close to each other and indicate high radiation efficiency.

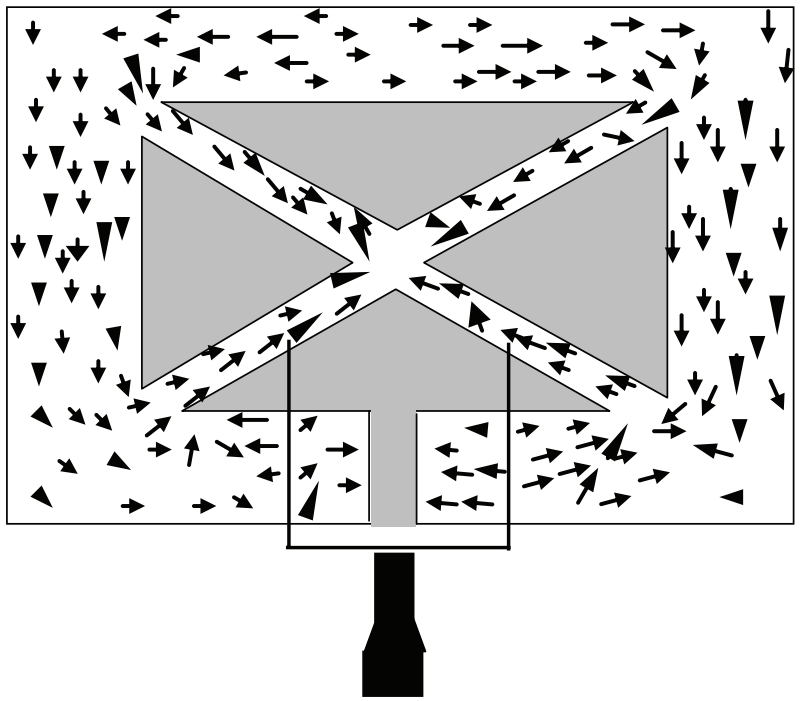

FIGURE 7: Simulated electric field distribution on the slots at the frequency of $10 \mathrm{GHz}$.

This figure also shows that above $10.5 \mathrm{GHz}$ the directivity and gain at boresight increase and it is a reason for this: each slot of the cross-slot is a branch of the square ring. These branches have the $W_{t}=1 \mathrm{~mm}$ and this is less than $W_{S}=6 \mathrm{~mm}$. This causes high current distribution flows to the cross-slot rather than square-ring slot and the gain increases at boresight above the $10.5 \mathrm{GHz}$. So the combination of the cross-slot and square ring slot improves the gain and directivity more than that in [9]. Figure 6 shows the measured maximum gain and gain at boresight.

This figure shows that the gain at boresight is more than $2 \mathrm{dBi}$ and is relatively constant from 8 to $12 \mathrm{GHz}$. The electric field distribution on the square ring and cross-slot for proposed antenna was simulated with the IE3D simulation software. Figure 7 shows the electric field distribution on the slots.

Figures 8 and 9 show the measured H-plane ( $x z$ plane) and E-plane ( $y z$ plane) radiation patterns for both co- and cross-polarizations at $f=3.5,5.5,7.5,9.5$, and $10.5 \mathrm{GHz}$. From the results, it is concluded that the proposed antenna in operating frequencies provides the same polarization planes and similar radiation patterns.

To use the antenna as a linearly polarized antenna, the radiation pattern in the E-plane is better than that in $\mathrm{H}$-plane. The E- and H-plane patterns start to introduce spurious radiation in high frequency (i.e., from $8.5 \mathrm{GHz}$ ) because the U-shaped stub length is almost equal to a half wavelength. However, the radiation patterns start to change in high frequencies and show higher directivities in other directions. In the E-plane, the cross-polar radiation is at least $-10 \mathrm{~dB}$ less than the copolar radiation. 


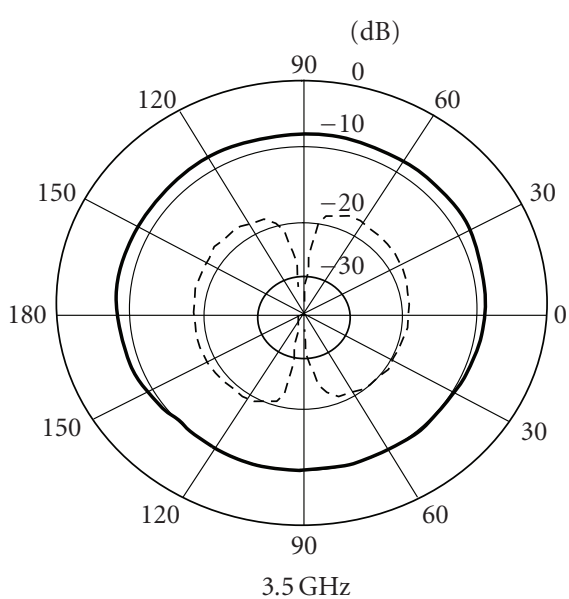

(a)

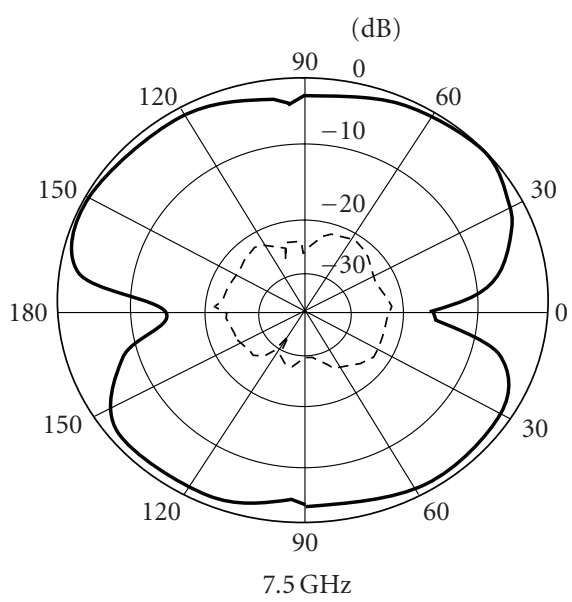

(c)

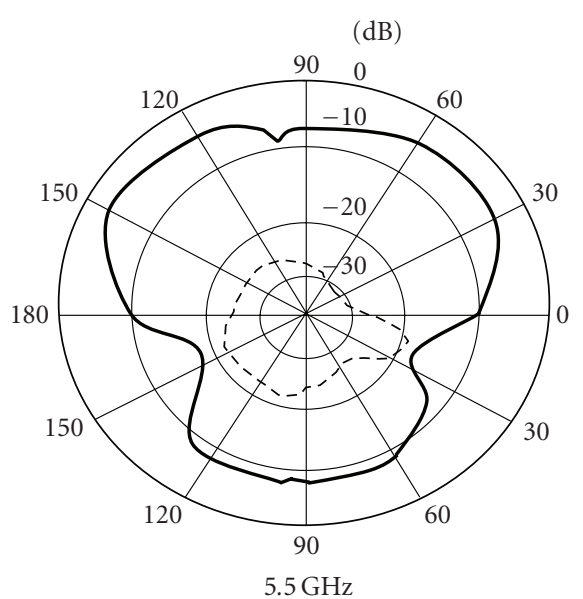

(b)

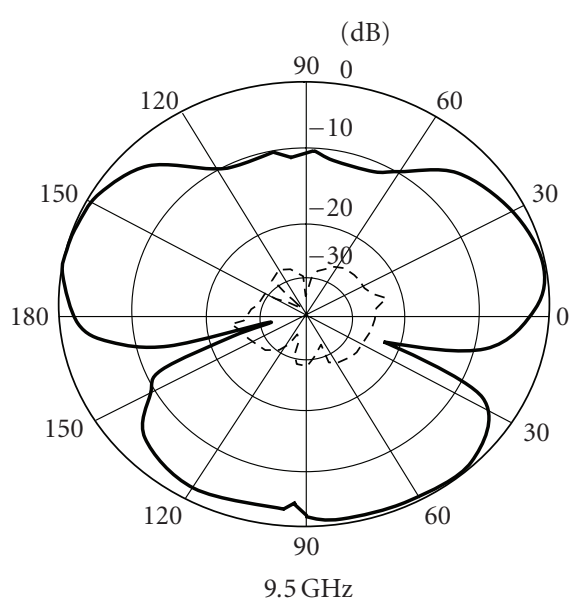

(d)

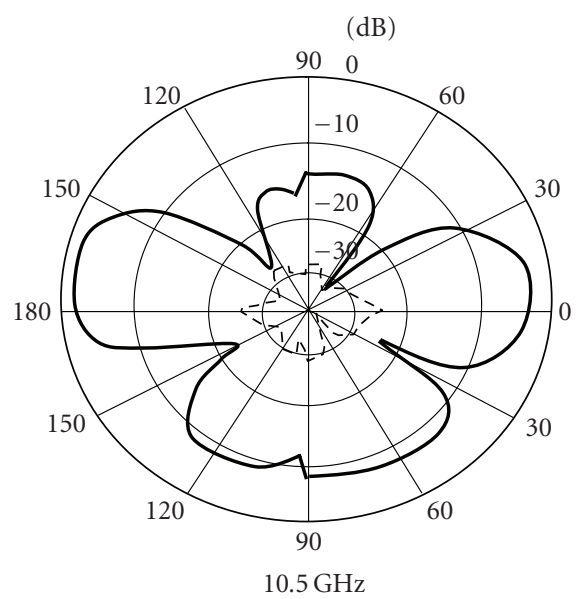

(e)

FIGURE 8: Measured radiation pattern of cross-slot antenna in H-plane $\left(\varphi=0^{\circ}\right)$. The solid line is copolar and the dash line is cross-polar component. 


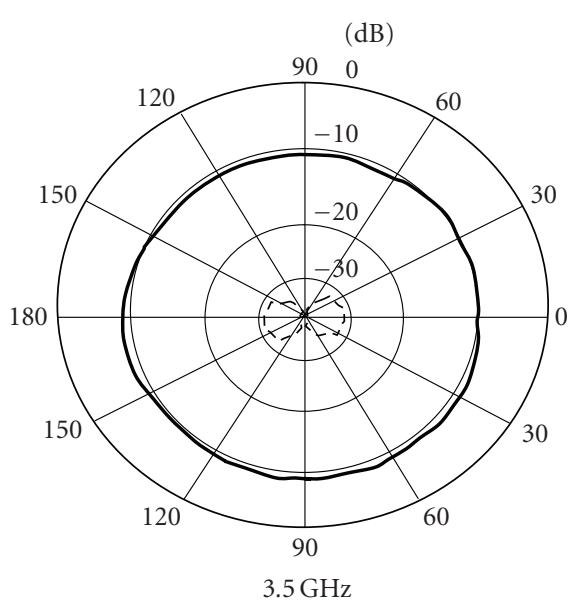

(a)

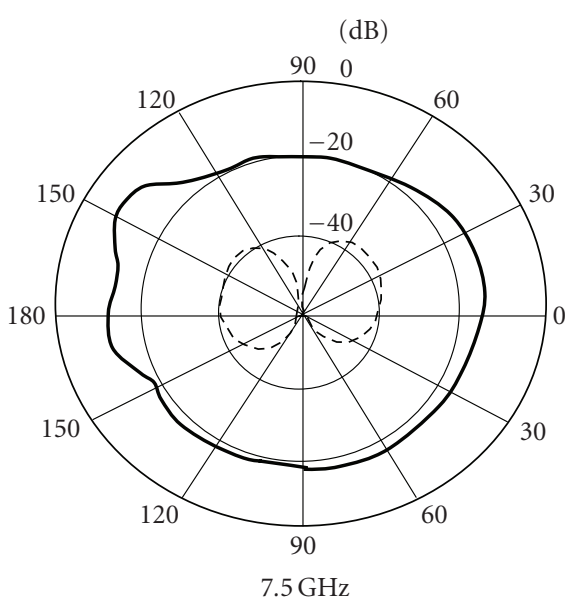

(c)

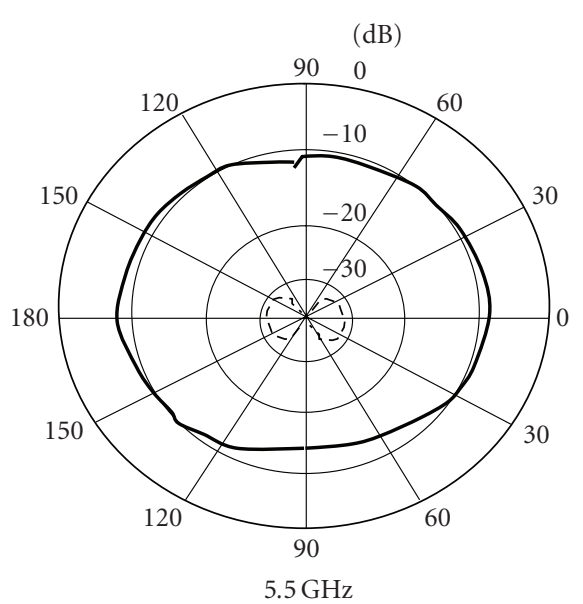

(b)

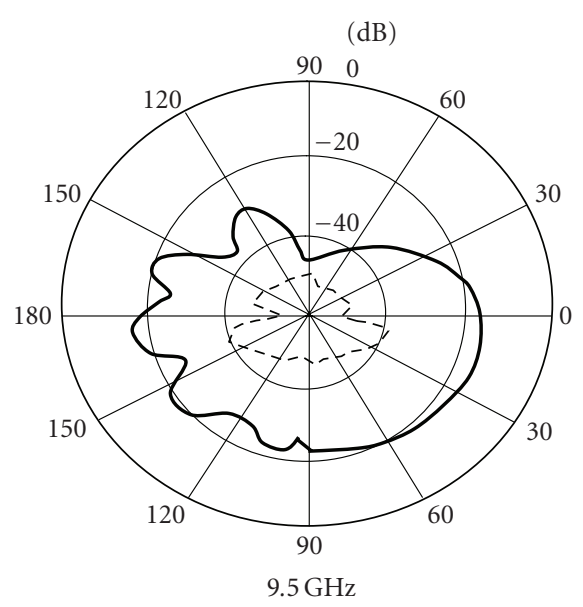

(d)

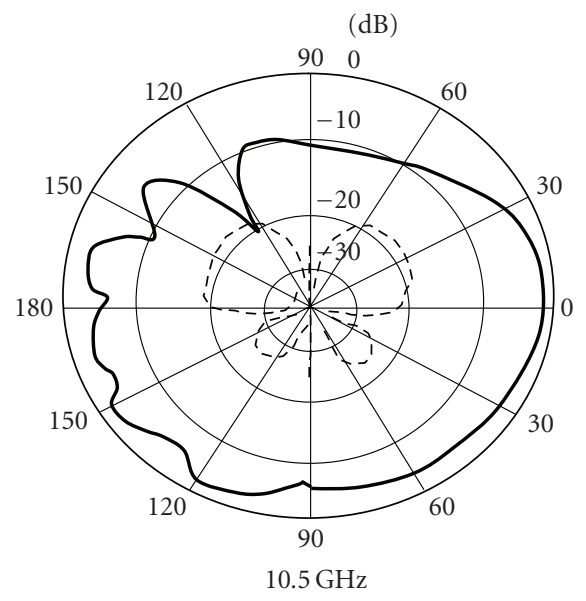

(e)

FIgURE 9: Measured radiation pattern of cross-slot antenna in E-plane $\left(\varphi=90^{\circ}\right)$. The solid line is copolar and the dash line is cross-polar component. 


\section{CONCLUSIONS}

A novel microstrip square-ring slot is merged by cross-slot and fed with a U-shaped tuning stub. The proposed antenna has been designed, simulated, optimized, and measured for the broadband operation. The novel antenna promotes gain, impedance bandwidth, and radiation pattern. The proposed antenna provides a good impedance matching from $3 \mathrm{GHz}$ to $12 \mathrm{GHz}$. This antenna has a favorable field gain across the matching band as a desirable feature for UWB applications. The gain and directivity at boresight are close to each other and provide high radiation efficiency.

\section{REFERENCES}

[1] "FCC report and order for part 15 acceptance of ultra wideband (UWB)System from 3.1-10.6 GHz," Washington, DC, USA, 2002.

[2] P. H. Rao, "Feed effects on the dimensions of wideband slot antennas," Microwave and Optical Technology Letters, vol. 40, no. 1, pp. 77-79, 2004.

[3] P. H. Rao, V. F. Fusco, and R. Cahill, "Linearly polarised radial stub fed high performance wideband slot antenna," Electronics Letters, vol. 37, no. 6, pp. 335-337, 2001.

[4] J.-Y. Sze and K.-L. Wong, "Bandwidth enhancement of a microstrip-line-fed printed wide-slot antenna," IEEE Transactions on Antennas and Propagation, vol. 49, no. 7, pp. 10201024, 2001.

[5] Y. W. Jang, "Broadband cross-shaped microstrip-fed slot antenna," Electronics Letters, vol. 36, no. 25, pp. 2056-2057, 2000 .

[6] R. Chair, A. A. Kishk, and K. F. Lee, "Ultrawide-band coplanar waveguide-fed rectangular slot antenna," IEEE Antennas and Wireless Propagation Letters, vol. 3, no. 1, pp. 227-229, 2004.

[7] N. Behdad and K. Sarabandi, "A wide-band slot antenna design employing a fictitious short circuit concept," IEEE Transactions on Antennas and Propagation, vol. 53, no. 1, pp. 475-482, 2005.

[8] F. G. Kharakhili, M. Fardis, G. Dadashzadeh, A. Ahmadi, and N. Hojjat, "Circular slot with a novel circular microstrip open ended microstrip feed for UWB applications," Progress in Electromagnetics Research, vol. 68, pp. 161-167, 2007.

[9] S. Sadat, M. Fardis, F. Geran, and G. Dadashzadeh, "A compact microstrip square-ring slot antenna for UWB applications," Progress in Electromagnetics Research, vol. 67, pp. 173-179, 2007.

[10] R. Chair, A. A. Kishk, K.-F. Lee, C. E. Smith, and D. Kajfez, "Microstrip line and CPW FED ultra wideband slot antennas with U-shaped tuning stub and reflector," Progress in Electromagnetics Research, vol. 56, pp. 163-182, 2006.

[11] “IE3D 9.1 Electromagnetic simulation software," Zeland software, Inc., Fremont, Calif, USA.

[12] "Advanced design system," Agilent Technologies, Palo Alto, Calif, USA. 

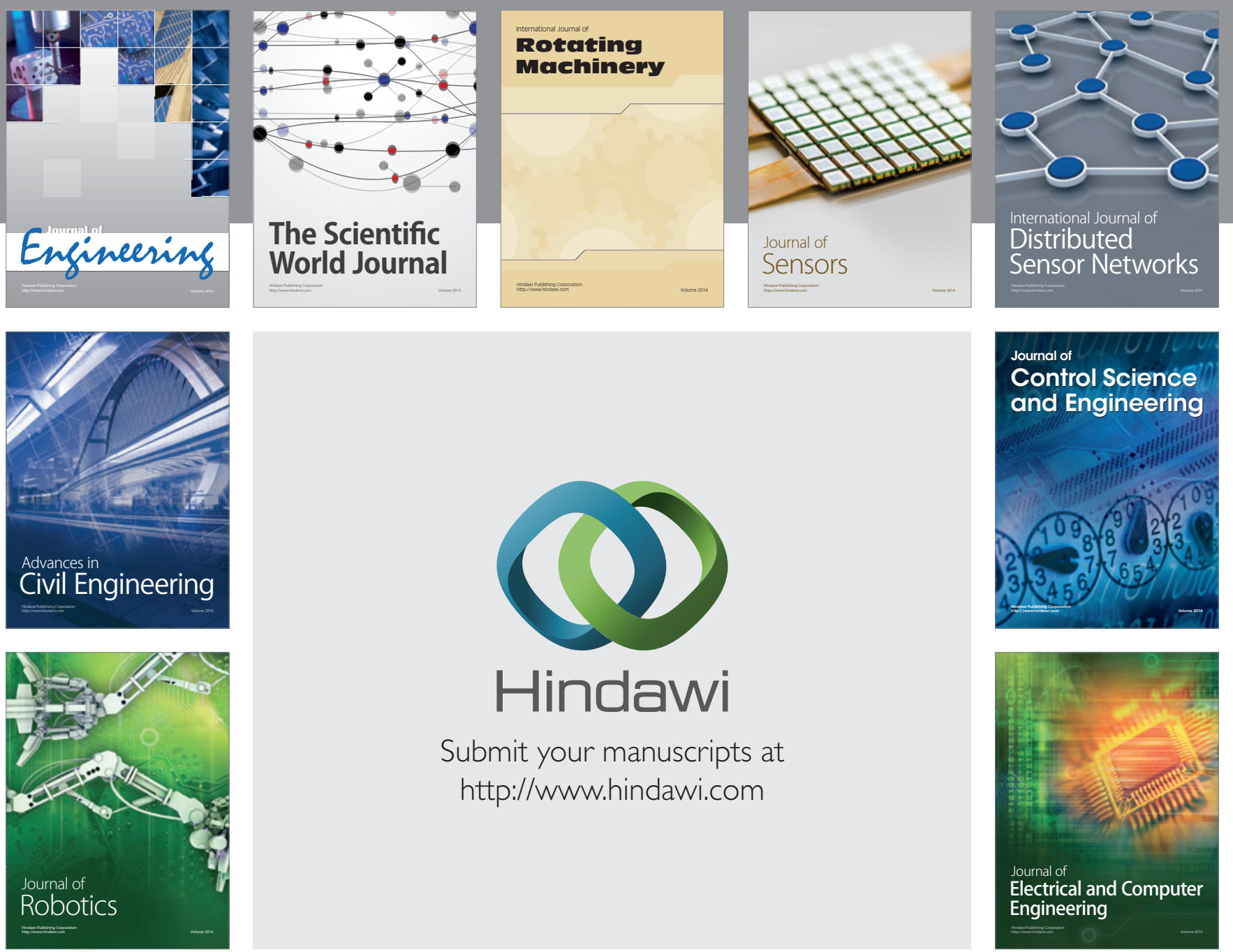

Submit your manuscripts at

http://www.hindawi.com
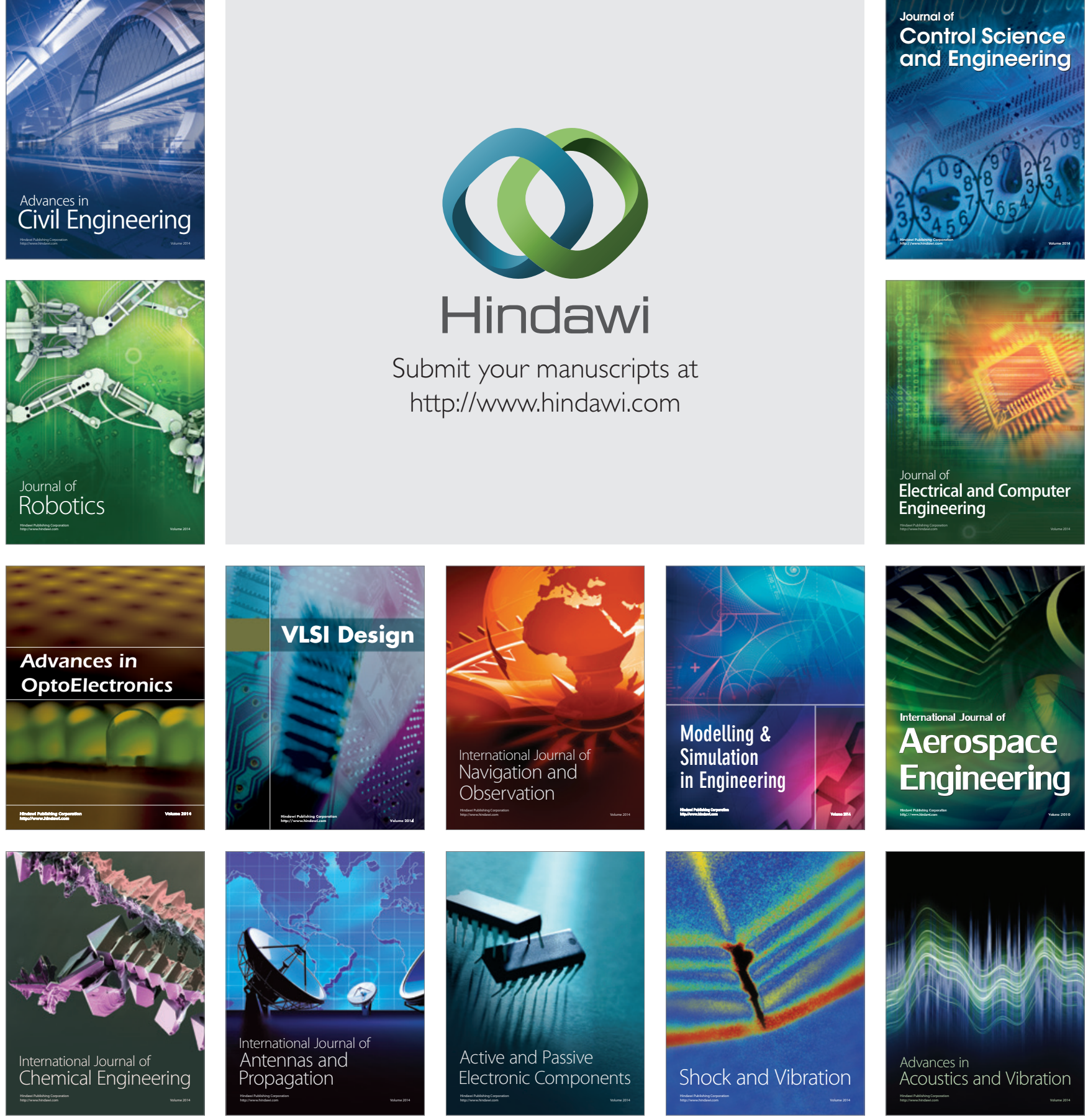